\title{
Fenologija cvatnje i pomološka svojstva sorti badema na području Beograda
}

\author{
Phenology of flowering and pomological traits of almond cultivars \\ in the region of Belgrade
}

\author{
D. Milatović, G. Zec, D. Đurović, Đ. Boškov
}

\section{SAŽETAK}

U radu su prikazani fenologija cvatnje i pomološka svojstva sedam sorti badema Prunus dulcis; ('Exinograd', 'Icar', 'Mari de Stepa', 'Nessebar', 'Miagkoskorlupniy', 'Prianiy' i 'Retsou') na području Beograda. Ispitivana je fenofaza cvatnje (početak, puna cvatnja, kraj, trajanje i obilnost) kao i svojstva ploda (masa i dimenzije ploda, debljina ljuske, masa i randman jezgre, sadržaj ulja i mineralnih tvari). Prosječno vrijeme cvatnje ispitivanih sorti je bilo u drugoj polovini ožujka i početkom travnja. Cvatnja je počinjala najranije kod sorti 'Exinograd' i 'Nessebar' (14. ožujka), a najkasnije kod sorte 'Mari de Stepa' (1. travnja). Prosječno trajanje cvatnje je variralo od 11 do 22 dana i bilo je duže kod sorti koje su ranije cvjetale. Sorte 'Icar' i 'Exinograd' su imale krupan plod (s masom iznad $5 \mathrm{~g}$ ), ali i najniži randman jezgre (ispod 30\%). S druge strane, sitan plod (ispod 2,5 g) su imale sorte 'Retsou', 'Miagkoskorlupniy', 'Nessebar' i 'Prianiy', koje su ujedno imale i najviši randman jezgre (47-52\%). Sadržaj ulja u jezgri je varirao $u$ intervalu od $49 \%$ ('Miagkoskorlupniy') do 60\% ('Mari de Stepa'). Sadržaj ukupnih mineralnih tvari je iznosio 3,03-3,31\%.

Ključne riječi: Prunus dulcis, cvatnja, plod, jezgra, sadržaj ulja

\begin{abstract}
The paper presents the phenology of flowering and pomological characteristics of seven almond Prunus dulcis cultivars; ('Exinograd', 'Icar', 'Mari de Stepa', 'Nessebar', 'Miagkoskorlupniy', 'Prianiy' and Retsou') in the region of Belgrade. The characteristics of the flowering phenophase (the beginning, the full flowering, the end of flowering, duration and abundance) as well as nut characteristics (nut weight and dimensions, shell thickness, weight of kernel, kernel/nut ratio, oil and total mineral contents) were examined. The average flowering time of the examined cultivars was the second half of March and early April. The flowering began first in the 'Exinograd' and
\end{abstract}


'Nessebar' cultivars (March $14^{\text {th }}$ ), and the last in 'Mari de Stepa' cultivar (April $1^{\text {st }}$ ). The average duration of flowering ranged from 11 to 22 days and it was longer in the cultivars with earlier flowering. Cultivars 'Icar' and 'Exinograd' had a large nut (weighing above $5 \mathrm{~g}$ ), but also the lowest kernel/nut ratio (below 30\%). On the other hand, small nut (under $2.5 \mathrm{~g}$ ) was found in cultivars 'Retsou', 'Miagkoskorlupniy', 'Nessebar' and 'Prianiy', which also had the highest kernel/nut ratio (47-52\%). The oil content in the kernel varied from $49.06 \%$ ('Miagkoskorlupniy') to $60.35 \%$ ('Mari de Stepa'). The total mineral content (ash) ranged from $3.03 \%$ to $3.31 \%$.

Key words: Prunus dulcis, flowering, fruit, kernel, oil content

\section{UVOD}

Badem [Prunus dulcis (Mill.) D.A.Webb] je lupinasta voćna vrsta koja se najviše uzgaja u područjima sa suptropskom klimom, koju karakteriziraju blage zime i topla i suha ljeta. U Srbiji se on uzgaja vrlo malo, uglavnom na okućnicama, a najviše na području Fruške Gore i u okolini Beograda. Glavni razlog za malu proizvodnju badema je njegova neredovita rodnost, u prvom redu zbog rane cvatnje i osjetljivosti na kasne proljetne mrazeve. Pravilnim izborom sorti i položaja pri podizanju nasada može se izbjeći ili umanjiti rizik od gubitka roda (Čolić i sur., 2005.).

Ninkovski i sur. (1991.) proučavali su svojstva osam sorti badema na području Pančevačkog rita i kao najbolje za uzgajanje u ovom području preporučili su sorte 'Marcona', 'Texas' i 'Nonpareil'. Zec i sur. (1999.) su ispitivali cvatnju četiriju sorti badema na području Padinske Skele i ustanovili da ona počinje po završetku cvatnje marelice i odvija se usporedo sa cvatnjom breskve. Na području Slankamenačkog brega u Vojvodini na okućnicama se uzgajaju sjemenjaci badema nepoznatog porijekla, koji se odlikuju velikom varijabilnošću svojstava (Čolić i Zec, 2007.; Čolić i sur., 2009.). Milatović i sur. (2013.) su ispitivali pomološka svojstva pet sorti badema na području Šumadije, od kojih su najbolja svojstva imale sorte 'Tuono' i 'Ferragnes'.

Cilj ovog rada je bio proučavanje pomoloških svojstava sedam sorti badema na području Beograda da bi se utvrdila mogućnost njihovog uzgajanja u ovom području.

\section{MATERIJAL I METODE RADA}

Istraživanja su provedena $u$ nasadu badema koji se nalazi na Oglednom dobru „Radmilovac“ Poljoprivrednog fakulteta u Beogradu. Proučavano je 
sedam sorti, od kojih su tri porijeklom iz Rumunjske: 'Exinograd', 'Icar' i 'Mari de Stepa', dvije iz Ukrajine: 'Miagkoskorlupniy' i 'Prianiy', a po jedna sorta iz Bugarske ('Nessebar') i Grčke ('Retsou'). Nasad je podignut 2006. godine, podloga je sjemenjak vinogradarske breskve [Prunus persica (L.) Batsch.], uzgojni oblik poboljšana piramidalna kruna, a razmak sadnje $4,5 \mathrm{~m} \times 2,5 \mathrm{~m}$. U nasadu su primjenjivane standardne agrotehničke i pomotehničke mjere, bez primjene navodnjavanja.

Fenologija cvatnje praćena je u razdoblju od četiri godine (2012 - 2015). Cvatnja je praćena prema preporukama Međunarodne radne grupe za polinaciju: početak cvatnje - kada se otvori $10 \%$ cvjetova, puna cvatnja - kada se otvori $80 \%$ cvjetova, a kraj cvatnje - kada otpadne 90\% kruničnih listića (Wertheim, 1996.).

Pomološka svojstva ploda su ispitivana u razdoblju od dvije godine (2014. 2015.) na uzorku od 25 plodova po sorti. Masa plodova određivana je nakon njihovog sušenja, mjerenjem na vagi "Mettler" preciznosti $0,01 \mathrm{~g}$ i izražena je $\mathrm{u}$ g. Dimenzije ploda (dužina, širina i debljina) i debljina ljuske su mjerene pomoću šublera i izražene su u mm. Randman jezgre je izračunat kao količnik mase jezgre i mase ploda i izražen je u \%. Na osnovu randmana jezgre izvršena je podjela sorti na osnovu klasifikacije koju su predložili Battle i sur. (2017.): vrlo tvrda ljuska (randman ispod 30\%), tvrda ljuska (randman 30-40\%), polumeka ljuska (randman 40-50\%), meka ljuska (randman 50-60\%) i vrlo meka ljuska (randman iznad 60\%).

Sadržaj ulja je određen ekstrakcijom sa petrol-eterom u Soxhlet aparatu (Faithfull, 2002.). Sadržaj ukupnih mineralnih tvari (pepeo) određivan je spaljivanjem na temperaturi od $550{ }^{\circ} \mathrm{C}$ (Faithfull, 2002.).

Meteorološki podaci u periodu istraživanja (2012. - 2015. godine) prikazani su u tablici 1. Srednje godišnje temperature zraka su varirale u intervalu 12,5$12,7{ }^{\circ} \mathrm{C}$, a godišnja suma padavina od $426 \mathrm{~mm}$ (2012.) do $918 \mathrm{~mm}$ (2014.). Apsolutna minimalna temperatura od $-20,7^{\circ} \mathrm{C}$ registrirana je 9 . veljače 2012 . godine. $\mathrm{U}$ svim godinama istraživanja u periodu cvatnje badema registrirani su kasni proljetni mrazevi čiji je intenzitet bio od $-1,8{ }^{\circ} \mathrm{C}\left(2014\right.$.) do $-3,5{ }^{\circ} \mathrm{C}$ (2015.).

Podaci za svojstva ploda su obrađeni statistički metodom analize varijance za dvofaktorijalni uzorak korištenjem računalnog programa 'Statistica version 8' (StatSoft, Inc., Tulsa, Oklahoma, USA). Značajnost razlika između srednjih vrijednosti utvrđena je pomoću LSD testa višestrukih intervala za vjerojatnosti 0,05 i 0,01 . 
Tablica 1.: Srednje mjesečne temperature zraka, apsolutne minimalne temperature zraka i mjesečne sume oborina na Oglednom dobru "Radmilovac" Poljoprivrednog fakulteta u Beogradu u periodu istraživanja (2012-2015. godine)

Table 1 Average monthly air temperatures, absolute minimum air temperatures and sums of precipitation at the Experimental farm 'Radmilovac' of the Faculty of Agriculture in Belgrade during the period of study (2012-2015)

\begin{tabular}{|l|c|c|c|c|c|c|c|c|c|c|c|c|}
\hline Months & \multicolumn{3}{|c|}{$\begin{array}{c}\text { Srednje mjesečne } \\
\text { temperature zraka }\left({ }^{\circ} \mathrm{C}\right) \\
\text { Average monthly air } \\
\text { temperatures, }{ }^{\circ} \mathrm{C} \text { ) }\end{array}$} & \multicolumn{3}{c|}{$\begin{array}{c}\text { Apsolutne minimalne } \\
\text { temperature zraka }\left({ }^{\circ} \mathrm{C}\right) \\
\text { (Absolute minimum } \\
\left.\text { air temperatures, }{ }^{\circ} \mathrm{C}\right)\end{array}$} & \multicolumn{3}{c|}{$\begin{array}{c}\text { Srednje mjesečne } \\
\text { sume oborina }(\mathrm{mm}) \\
\text { Average monthly sums } \\
\text { of precipitation, mm) }\end{array}$} \\
\hline Years & 2012 & 2013 & 2014 & 2015 & 2012 & 2013 & 2014 & 2015 & 2012 & 2013 & 2014 & 2015 \\
\hline I & 1,3 & 2,4 & 3,9 & 2,8 & $-13,8$ & $-8,4$ & $-8,0$ & $-13,5$ & 84,4 & 69,0 & 14,0 & 37,2 \\
\hline II & $-3,7$ & 3,8 & 6,3 & 2,9 & $-20,7$ & $-7,5$ & $-7,2$ & $-9,6$ & 15,0 & 55,0 & 13,6 & 41,2 \\
\hline III & 8,9 & 5,7 & 9,8 & 7,2 & $-7,3$ & $-5,5$ & $-0,5$ & $-3,5$ & 3,0 & 93,8 & 50,2 & 107,4 \\
\hline IV & 13,1 & 13,4 & 12,7 & 12,1 & $-3,0$ & 1,5 & 3,6 & $-0,9$ & 66,2 & 24,2 & 72,6 & 31,0 \\
\hline V & 16,7 & 17,8 & 15,7 & 17,6 & 5,6 & 6,5 & 2,0 & 6,8 & 93,6 & 96,4 & 265,8 & 49,6 \\
\hline VI & 22,8 & 20,0 & 20,3 & 20,5 & 9,9 & 9,1 & 9,2 & 10,2 & 12,2 & 41,4 & 53,8 & 50,2 \\
\hline VII & 25,1 & 22,6 & 21,8 & 24,6 & 12,2 & 9,9 & 11,2 & 10,4 & 22,2 & 12,2 & 148,4 & 6,0 \\
\hline VIII & 24,0 & 23,5 & 21,0 & 24,1 & 8,5 & 12,1 & 8,3 & 11,1 & 4,0 & 23,6 & 83,0 & 50,0 \\
\hline IX & 20,0 & 16,2 & 17,1 & 19,0 & 3,8 & 6,0 & 5,3 & 6,0 & 18,4 & 69,4 & 99,4 & 77,4 \\
\hline X & 12,9 & 13,5 & 12,7 & 11,2 & $-3,6$ & $-1,7$ & $-1,9$ & 0,6 & 48,0 & 34,8 & 54,8 & 63,8 \\
\hline XI & 9,2 & 8,7 & 8,2 & 7,8 & 0,2 & $-4,8$ & $-4,4$ & $-2,8$ & 31,8 & 39,6 & 13,8 & 50,8 \\
\hline XII & 0,9 & 1,9 & 3,2 & 3,0 & $-12,4$ & $-7,4$ & $-15,9$ & $-9,0$ & 27,2 & 9,2 & 49,0 & 6,8 \\
\hline
\end{tabular}

\section{REZULTATI I RASPRAVA}

Cvatnja je jedna od najvažnijih fenofaza u godišnjem ciklusu razvoja badema, a ujedno i kritična faza od koje u velikoj mjeri zavisi rodnost ove voćke. Badem se odlikuje kratkim periodom biološkog zimskog mirovanja i ranim vremenom cvatnje. Početak cvatnje prvenstveno ovisi o potrebi za relativno niskim temperaturama (chilling units) u tijeku dubokog zimskog mirovanja, a u znatno manjoj mjeri o akumulaciji topline tijekom ekološkog mirovanja (Egea i sur., 2003.).

Prosječno vrijeme cvatnje ispitivanih sorti badema je bilo u drugoj polovini ožujka i početkom travnja (Tablica 2). Cvatnja je počinjala najranije kod sorti 'Exinograd' i 'Nessebar' (14. ožujka), a najkasnije kod sorte 'Mari de Stepa' (1. travnja).

Po godinama ispitivanja uočeno je veliko variranje vremena cvatnje. Najranija cvatnja bila je u 2014. godini, kada je prosječan datum početka cvatnje za sve sorte bio 4. ožujak, a kod najranijih sorti cvatnja je počela još 23. veljače. Najkasnija cvatnja bila je u 2013. godini, kada je prosječan datum 
početka cvatnje bio 30. ožujak, dok kod sorte 'Mari de Stepa' on bio tek 12. travnja.

Prosječan datum početka cvatnje badema u ovom području je bio 20 . ožujak. To je znatno ranije u odnosu na istraživanje Ninkovskog i sur. (1991.) u kojem je prosječan datum početka cvatnje badema u uvjetima Pančevačkog rita bio 6. travnja, kao i ispitivanja Zeca i sur. (1999.) u uvjetima Padinske Skele, gde je ovaj datum bio 5. travnja.

Tablica 2.: Fenologija cvatnje sorti badema, trajanje i obilnost cvatnje (prosječne vrijednosti, 2012-2015. godine)

Table 2 Phenology of flowering, duration and abundance of flowering of almond cultivars (average values, 2012-2015)

\begin{tabular}{|l|c|c|c|c|c|}
\hline $\begin{array}{c}\text { Sorta } \\
\text { (Cultivar) }\end{array}$ & $\begin{array}{c}\text { Početak } \\
\text { cvatnje } \\
\text { (Start of } \\
\text { flowering) }\end{array}$ & $\begin{array}{c}\text { Puna } \\
\text { cvatnja } \\
\text { (Full } \\
\text { flowering) }\end{array}$ & $\begin{array}{c}\text { Kraj } \\
\text { cvatnje } \\
\text { (End of } \\
\text { flowering) }\end{array}$ & $\begin{array}{c}\text { Trajanje } \\
\text { u danima } \\
\text { (Duration } \\
\text { in days) }\end{array}$ & $\begin{array}{c}\text { Obilnost } \\
\text { po skali 0-5 } \\
\text { (Abundance } \\
\text { using scale 0-5) }\end{array}$ \\
\hline Exinograd & 14.03. & 22.03. & 03.04. & 20 & 2,5 \\
\hline Icar & 18.03. & 24.03. & 03.04. & 16 & 3,1 \\
\hline Mari de Stepa & 01.04. & 03.04. & 12.04. & 11 & 4,5 \\
\hline Miagkoskorlupniy & 22.03. & 27.03. & 06.04. & 15 & 3,0 \\
\hline Nessebar & 14.03. & 23.03. & 05.04. & 22 & 3,8 \\
\hline Prianiy & 20.03. & 26.03. & 06.04. & 17 & 3,3 \\
\hline Retsou & 27.03. & 31.03. & 09.04. & 13 & 2,7 \\
\hline
\end{tabular}

Iako je u ovo istraživanje bilo uključeno samo sedam sorti badema, amplituda između sorti s najranijim i najpoznijim vremenom cvatnje je bila relativno velika. Ona je iznosila prosječno 18 dana, dok je po godinama varirala od 10 do 24 dana. To potvrđuje navode Segura i sur. (2017.) da badem ima najširi raspon cvatnje među svim voćkama.

Prosječno trajanje cvatnje je variralo od 11 do 22 dana. Najduža cvatnja (20-22 dana) bila je kod sorti najranijeg vremena cvatnje ('Nessebar' i 'Exinograd'). S druge strane, najkraća cvatnja (11-13 dana) bila je kod sorti najkasnijeg vremena cvatnje ('Mari de Stepa' i 'Retsou'). Cvatnja je bila najkraća (11,8 dana u prosjeku za sve sorte) u 2012. godini, koja se odlikovala najvišim temperaturama u fenofazi cvatnje (prosječno $11,9^{\circ} \mathrm{C}$ ). $\mathrm{S}$ druge strane, najduže trajanje cvatnje (23,3 dana) je bilo u 2014. godini, koja se odlikovala najranijom cvatnjom i nižim temperaturama $u$ toku trajanja ove fenofaze (prosječno $9,2^{\circ} \mathrm{C}$ ). 
D. Milatović i sur.: Fenologija cvatnje

i pomološka svojstva sorti badema na području Beograda

Tablica 3.: Prosječne vrijednosti pomoloških svojstava ploda za sorte badema u 2014 i 2015. godini

Table 3 Mean values of nut characteristics for almond cultivars in 2014 and 2015

\begin{tabular}{|l|c|c|c|c|c|}
\hline $\begin{array}{c}\text { Sorta } \\
(\text { Cultivar })\end{array}$ & $\begin{array}{c}\text { Masa } \\
(\text { Weight }) \\
(\mathrm{g})\end{array}$ & $\begin{array}{c}\text { Dužina } \\
(\text { Length }) \\
(\mathrm{mm})\end{array}$ & $\begin{array}{c}\text { Širina } \\
(\text { Diameter }) \\
(\mathrm{mm})\end{array}$ & $\begin{array}{c}\text { Debljina } \\
(\text { Width) } \\
(\mathrm{mm})\end{array}$ & $\begin{array}{c}\text { Debljina ljuske } \\
(\text { Shell thickness }) \\
(\mathrm{mm})\end{array}$ \\
\hline Exinograd & 5,08 & 36,06 & 23,46 & 15,76 & 3,45 \\
\hline Icar & 5,42 & 37,67 & 27,77 & 17,78 & 4,14 \\
\hline Mari de Stepa & 3,75 & 35,49 & 24,23 & 15,31 & 3,55 \\
\hline Miagkoskorlupniy & 2,01 & 32,14 & 21,35 & 14,87 & 1,68 \\
\hline Nessebar & 2,06 & 28,16 & 17,67 & 12,13 & 1,94 \\
\hline Prianiy & 2,29 & 33,32 & 21,85 & 14,78 & 2,09 \\
\hline Retsou & 1,74 & 31,06 & 15,99 & 11,64 & 1,78 \\
\hline LSD 0,05 & 0,24 & 1,18 & 0,91 & 0,57 & 0,17 \\
\hline LSD 0,01 & 0,32 & 1,56 & 1,20 & 0,75 & 0,22 \\
\hline
\end{tabular}

Prosječna obilnost cvatnje je bila najmanja kod sorte 'Exinograd' (ocjena 2,5), a najveća kod sorte 'Mari de Stepa' (ocjena 4,5). Velika obilnost cvatnje je značajna za osiguranje visoke rodnosti, jer veći broj cvjetova može djelimično nadoknaditi oštećenja zbog pojave mrazeva (Kodad i Socias i Company, 2008.).

Između ispitivanih sorti badema uočene su statistički značajne razlike za masu i dimenzije ploda, kao i za debljinu ljuske (Tablica 3). Masa ploda je varirala od 1,74 g kod sorte 'Retsou' do 5,42 g kod sorte 'Icar'. Dimenzije ploda su imale najviše vrijednosti kod sorte 'Icar'. Najmanju dužinu ploda imala je sorta 'Nessebar', dok su širina i debljina ploda bile najmanje kod sorte 'Retsou'. Debljina ljuske je varirala od 1,68 mm ('Miagkoskorlupniy') do 4,14 mm ('Icar').

Masa jezgre je bila najmanja kod sorte 'Retsou' $(0,83 \mathrm{~g})$, a najveća kod sorte 'Exinograd' (1,29 g) (Tablica 4). Prema podjeli koju su dali Socias i Company i sur. (2008.) najveći broj ispitivanih sorti (pet) imao je srednjokrupnu jezgru (masa 1,1-1,4 g). Dvije sorte ('Nessebar' i 'Miagkoskorlupniy') spadaju u grupu sorti sa sitnom jezgrom $(0,9-1,1 \mathrm{~g})$, dok sorta 'Retsou' spada u kategoriju s vrlo sitnom jezgrom (ispod $0,9 \mathrm{~g}$ ).

Randman jezgre je varirao od $23,30 \%$ ('Icar') do $51,83 \%$ ('Miagkoskorlupniy'). Na osnovu randmana jezgre, prema podjeli koju su dali Batlle i sur. (2017.) dvije proučavane sorte ('Exinograd' i 'Icar') imaju vrlo tvrdu ljusku (randman ispod 30\%), sorta 'Mari de Stepa' ima tvrdu ljusku (randman 30-40\%), tri sorte ('Nessebar', 'Retsou' i 'Prianiy') imaju polumeku 
ljusku (randman 40-50\%), dok sorta 'Miagkoskorlupniy' ima meku ljusku (randman 50-60\%).

Tablica 4.: Prosječne vrijednosti svojstava jezgre za sorte badema u 2014 i 2015. godini

Table 4 Mean values of kernel characteristics for almond cultivars in 2014 and 2015

\begin{tabular}{|l|c|c|c|c|}
\hline $\begin{array}{l}\text { Sorta } \\
\text { (Cultivar) }\end{array}$ & $\begin{array}{c}\text { Masa jezgre } \\
\text { (Kernel weight) } \\
(\mathrm{g})\end{array}$ & $\begin{array}{c}\text { Randman jezgre } \\
(\text { Kernel/nut ratio) } \\
(\%)\end{array}$ & $\begin{array}{c}\text { Sadržaj ulja } \\
(\text { Oil content) } \\
(\%)\end{array}$ & $\begin{array}{c}\text { Sadržaj pepela } \\
\text { (Ash content) } \\
(\%)\end{array}$ \\
\hline Exinograd & 1,29 & 25,39 & 57,27 & 3,25 \\
\hline Icar & 1,26 & 23,30 & 55,54 & 3,03 \\
\hline Mari de Stepa & 1,18 & 31,49 & 60,35 & 3,31 \\
\hline Miagkoskorlupniy & 1,04 & 51,83 & 49,06 & 3,15 \\
\hline Nessebar & 0,98 & 47,49 & 59,88 & 3,12 \\
\hline Prianiy & 1,14 & 49,60 & 54,31 & 3,07 \\
\hline Retsou & 0,83 & 47,56 & 58,73 & 3,14 \\
\hline LSD 0,05 & 0,09 & - & 1,81 & 0,22 \\
\hline LSD 0,01 & 0,12 & - & 2,49 & 0,30 \\
\hline
\end{tabular}

Sadržaj ulja u jezgri je varirao u intervalu od 49,06\% ('Miagkoskorlupniy') do 60,35\% ('Mari de Stepa'). U pogledu ovog parametra razlike između ispitivanih sorti su bile statistički značajne. Prema podjeli koju su dali Torabi i sur. (2011.) najveći broj ispitivanih sorti (pet) ima vrlo visok sadržaj ulja (iznad $55 \%$ ). 'Prianiy' spada u kategoriju sorti s dobrim sadržajem ulja (50-55\%), a 'Miagkoskorlupniy' u kategoriju sa srednjim sadržajem ulja (45-50\%). Sadržaj ulja je manje varirao između godina ispitivanja nego između ispitivanih sorti.

Sadržaj ukupnih mineralnih tvari (pepeo) u jezgri je iznosio prosječno 3,17\%. Najniži sadržaj je utvrđen kod sorte 'Icar' (3,03\%), a najviši kod sorte 'Mari de Stepa' (3,31\%).

Dobiveni rezultati o sadržaju ulja i mineralnih tvari u jezgri badema su u granicama vrijednosti koje su dobvene u prethodnim istraživanjima (Aslanta i sur., 2001.; Kodad i sur., 2010.; Čolić i sur., 2012.; Yildirim et al., 2016.).

\section{ZAKLJUČAK}

Prosječno vrijeme cvatnje ispitivanih sorti badema je bilo u drugoj polovini ožujka i početkom travnja. Rano vrijeme cvatnje predstavlja ograničavajući 
faktor za uzgajanje badema u uvjetima Beograda. Među ispitivanim sortama najkasnije vrijeme cvatnje su imale 'Mari de Stepa' i 'Retsou'. Njihovim uzgajanjem može se smanjiti rizik od oštećenja generativnih organa zbog pojave proljetnih mrazeva.

Sorte 'Icar' i 'Exinograd' imale su krupan plod (s masom iznad 5 g), ali i najniži randman jezgre (ispod 30\%). S druge strane, sitan plod (ispod 2,5 g) su imale sorte 'Retsou', 'Miagkoskorlupniy', 'Nessebar' i 'Prianiy', koje su ujedno imale i najviši randman jezgre (47-52\%). Većina ispitivanih sorti odlikovala se visokim sadržajem ulja u jezgri (iznad 55\%), a najviši sadržaj $(60,35 \%)$ je imala sorta 'Mari de Stepa'.

\section{LITERATURA}

ASLANTA, R., GÜLERYÜZ, M., TURAN, M. (2001.): Some chemical contents of selected almond (Prunus amygdalus Batsch) types. Options Méditerranéennes, 56: 347-350.

BATLLE, I., DICENTA, F., SOCIAS I COMPANY, R., GRADZIEL, T.M., WIRTHENSOHN, M., DUVAL, H., VARGAS, F.J. (2017.): Classical genetics and breeding. In: Almonds: Botany, Production and Uses (Socias i Company, R. and Gradziel, T.M., eds.), CAB International, Wallingford, UK, pp. 111-148.

ČOLIĆ, S., ZEC, G. (2007.): Morphological and pomological traits variability of almond genotypes from Slankamen hill population. Genetika, 39: 291296.

ČOLIĆ, S., ZEC, G., MARINKOVIĆ, D., MILOSAVLJEVIĆ, S., JANKOVIĆ, Z. (2005.): Značaj izbora genotipova i položaja pri podizanju zasada badema i breskve. Zbornik naučnih radova Instituta PKB Agroekonomik, 11(5): 96-103.

ČOLIĆ, S., ZEC, G., JANKOVIĆ, Z., RAHOVIĆ, D. (2009.): Selekcija genotipova badema [Prunus dulcis (Mill.) D.A. Webb.] na području Slankamenačkog brega. Zbornik naučnih radova Instituta PKB Agroekonomik, 15(5): 69-75. 
ČOLIĆ, S., RAKONJAC, V., ZEC, G., NIKOLIĆ, D., FOTIRIĆ AKŠIĆ, M. (2012.): Morphological and biochemical evaluation of selected almond [Prunus dulcis (Mill.) DA Webb] genotypes in northern Serbia. Turkish Journal of Agriculture and Forestry, 36(4): 429-438.

EGEA, J., ORTEGA, E., MARTÍNEZ-GÓMEZ, P., DICENTA, F. (2003.): Chilling and heat requirements of almond cultivars for flowering. Environmental and Experimental Botany, 50(1): 79-85.

FAITHFULL N.T. (2002.): Methods in agricultural chemical analysis: a practical handbook. CABI Publishing, Wallingford, UK.

KODAD, O., SOCIAS I COMPANY, R. (2008.): Significance of flower bud density for cultivar evaluation in almond. HortScience, 43: 1753-1758.

KODAD, O., ESTOPAÑAN, G., JUAN, T., MOLINO, F., MAMOUNI, A., MESSAOUDI, Z., LAHLOU, M., SOCIAS I COMPANY, R. (2010.): Plasticity and stability in the major fatty acid content of almond kernels grown under two Mediterranean climates. Journal of Horticultural Science and Biotechnology, 85(5): 381-386.

MILATOVIĆ, D., ĐUROVIĆ, D., ZEC, G., ČOlOVEIĆ, A. (2013.): Pomološke osobine sorti badema na području Šumadije. Zbornik naučnih radova Instituta PKB Agroekonomik, 19(5): 47-54.

NINKOVSKI, I., JANKOVIĆ, D., ĐAKOVIĆ, M., POPOVIĆ, D. (1991.): Izučavanje nekih mediteranskih i kalifornijskih sorti badema u beogradskom voćarskom području. Nauka u praksi, 21(1): 15-32.

SEGURA, J. M. A., I COMPANY, R. S., KODAD, O. (2017.): Late-blooming in almond: A controversial objective. Scientia Horticulturae, 224: 61-67.

SOCIAS I COMPANY, R., KODAD, O., ALONSO, J.M., GRADZIEL, T.M. (2008.): Almond quality: a breeding perspective. Horticultural Reviews, 34 : 197-238.

TORABI, A., IMANI, A., RABIEI, V. (2011.): Oil content of seeds of 25 Iranian, European and American almond genotypes and cultivars. Acta Horticulturae, 912: 367-369.

WERTHEIM, S.J. (1996.): Methods for cross pollination and flowering assessment and their interpretation. Acta Horticulturae, 423: 237-241. 
YILDIRIM, A. N., AKINCI-YILDIRIM, F., ŞAN, B., SESLI, Y. (2016.): Total oil content and fatty acid profile of some almond (Amygdalus communis L.) cultivars. Polish Journal of Food and Nutrition Sciences, 66(3): 173-178.

ZEC, G., ČOLIĆ, S., PEKIĆ, M., MARINKOVIĆ D. (1999.): Vreme cvetanja nekih sorti badema u uslovima Padinske Skele. Zbornik naučnih radova PKB Agroekonomik, 5(2): 19-24.

\section{Adresa autora - Author's address:}

Dragan Milatović, e-mail: mdragan@agrif.bg.ac.rs

Gordan Zec, Dejan Đurović, Đorđe Boškov

Univerzitet u Beogradu, Poljoprivredni fakultet,

Nemanjina 6, Beograd - Zemun, Srbija 